NBER WORKING PAPER SERIES

THE ECONOMICS OF CONTENT PROTECTION

Michael Mussa

Working Paper No. 1457

NATIONAL BUREAU OF ECONOMIC RESEARCH 1050 Massachusetts Avenue Cambridge, MA 02138

September 1984

The research reported here is part of the NBER's research program in International Studies and project in Productivity (World Economy). Any opinions expressed are those of the author and not those of the National Bureau of Economic Research. 


\title{
The Economics of Content Protection
}

\begin{abstract}
$\underline{\text { ABSTRACT }}$
In a model that allows smooth substitution between domestic and imported inputs, content protection distorts input choice but does not force a divergence between price and unit production cost. Content protection biases gains in technical efficiency away from those saving domestic input and toward those saving imported input. By increasing derived demand for the domestic input, a marginally effective content requirement benefits suppliers of this input. Increases in the content requirement above the marginally effective level increase such benefits to suppliers of the domestic input provided that the price elasticity of demand for the final product is less than a critical value. The consequences of content protection are not materially affected by monopoly in the domestic final product market or monopsony in the domestic input market unless such monopoly or monopsony are created by content protection. The situation of a monopolistic supplier of the domestic input is enhanced by content protection.
\end{abstract}

Michael Mussa

Graduate School of Business University of Chicago 1101 East 58th Street Chicago, Illinois 60637

(312) 962-7143 


\section{Introduction}

This paper analyzes economic effects of policies of content protection, such as the proposal to require automobiles sold in the United States to embody a prescribed minimum share of domestic value added. Similar policies have been implemented in a number of developing countries, as well as in Australia and canada. Included in this broad class of policies are both requirements that final goods assembled in a country should use a minimum amount of domestic input, and requirements that final goods exported to a country should use a minimum amount of domestic input in their foreign assembly processes. 1

To analyze the consequences of such policies of content protection, it is assumed that the final product is produced in accord with a neo-classical production function, specified in section 2, that employs domestic inputs and imported (or foreign) inputs. This specification allows for smooth substitution possibilities between domestic and imported inputs which, it is argued, characterize the situation of many industries that are the actual or potential subjects of content protection policies. This specification differs from that of Grossman (1981) who assumes that the imported material input is a perfect substitute for a domestically produced material input and that total material input (imported plus domestic) substitute against domestic labor in the production of final output. 2 Using the present specification, it is shown that a domestic content requirement, specified as a required minimum share of domestic input in the value of final product and enforced by a penalty tariff imposed against violators, raises the ratio of domestic input to imported input and creates a production distortion by raising unit production cost 
above the cost minimizing level. Because of the all-or-nothing nature of the enforcement penalty, however, content protection has the virtue of not inducing a distortion between the social cost of production (given the distortion of input choice) and the price charged to consumers of the final product. For this reason, content protection is preferable to a tariff on imported inputs or a subsidy on domestic inputs as a policy to increase the ratio of domestic to imported input in final output.

Content protection has less salutory effects when account is taken, in section 3 , of the effects on incentives for improvements in techincal efficiency. The private and social benefit of technical improvements that save on domestic input is artificially reduced and the private and social benefit of technical improvements that save on imported inputs is artificially increased by a domestic content requirement. Taking account of the cost of finding and implementing improvements in technical efficiency, therefore, content protection will impede progress in making production processes that employ domestic inputs more efficient, and will lead to excess investment in technical improvements that reduced required amounts of imported inputs. The effects of content protection on the equilibrium price and quantity of the domestic input are obviously of central concern to the suppliers of this input, who are frequently the most ardent advocates of content protection. In section 4 , it is shown that under competitive market conditions, a small increase in the domestic content requirement above the level that firms would voluntarily choose will increase the derived demand for the domestic input and lassuming a positive but less than infinite elasticity of supply of the domestic input) will also increase the equilibrium quantity and price of the domestic input. The direct effect of further increases in the domestic content requirement above this marginally effective level are at least 
partially offset by reductions in demand for the final product resulting from increases in its price due to increased unit cost that are the consequence of content protection. However, provided that the price elasticity of demand for the final product is less than a critical value, the overall effect of an increase in the donestic content requirement will still be to increase the derived demand for the domestic input and, hence, the equilibrium quantity and price of that input.

The condition for an increase in the content requirement to increase demand for the domestic input is modified in situations, examined in section 5, where only foreign firms (and not domestic firms) are effectively constrained by content protection. In such situations, the own price elasticity of demand for the foreign firms' product is likely to be larger than the overall price elasticity of demand for the products of domestic and the foreign firms because an increase in the price of the foreign firms' product shifts demand toward the domestic firms' product. Hence, the increase in the price of the foreign firms' product due to an increased domestic content requirement will be a more powerful force in reducing demand for the domestic input. However, since a shift of demand toward the domestic product increases domestic firms' demands for the domestic input, the overall effect of an increase in the content requirement for foreign firms is still likely to be an increase in demand for the domestic input.

The implications of non-competitive behavior in the final product and domestic factor markets are examined in section 6 . Content protection does not alter the usual difference between monopolistic and competitive behavior by sellers of the final product or between monopsonistic and competitive behavior by buyers of the domestic input, unless content protection creates a monopoly or monopsony situation when one would not otherwise exist. Content 
protection, however, does interact in an interesting way with monopoly behavior of suppliers of the domestic input since it alters the elasticity of demand for this input in a way that can always be exploited by these suppliers.

The main results of this analysis of content protection are summarized in section 7, and extensions and modifications of these results are briefly discussed.

2. Effects on Input Choice, Production Cost and output Price The technology of the industry subject to content protection is assumed to be described by a neo-classical, linear homogeneous production function,

$$
X=F(I, D) \text { or } X / I \equiv x=f(d) \equiv F(I, d), \text { with } d \equiv D / I
$$

where $X$ is the quantity of final output, $I$ is the quantity of imported (or foreign) input, and $D$ is the quantity of domestic input. This production function applies equally well to a final product assembled at home using domestic and imported inputs, and to a final product assembled abroad using domestic and foreign inputs and then exported back to the home country. The smooth shape of the isoquants of this production function illustrated in figure 1 reflect the assumption that domestic input can be substituted continuously, but with increasing difficulty, for imported (or foreign) input. The idea is that as the required share of domestic content rises, production of more components and more assembly processes must employ domestic inputs, starting first with the production activities in which domestic inputs are relatively most efficient and moving progressively to activities where these inputs are less and less efficient in comparison with imported (or foreign) inputs. This description applies fairly well to the automobile industry which 


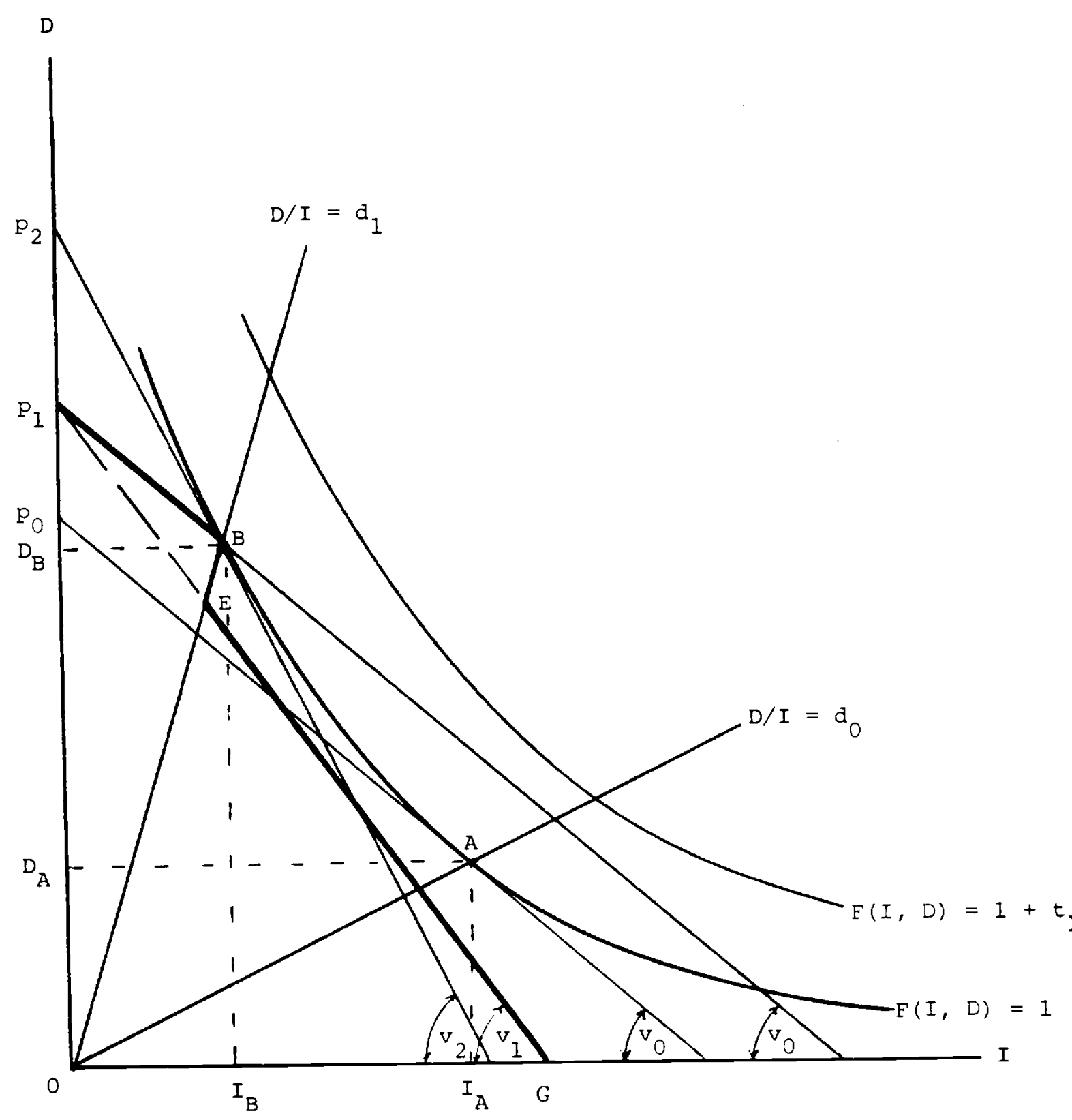

Fig.--1: The Effect of Content Protection on Input Choice and the Iso-cost Locus. 
is a favorite subject of such requirements in developing countries and a possible subject in the United States. Arguably, this description also applies to a wide range of manufactured goods, from apparel to televisions, that are or might become subjects of content protection. ${ }^{3}$

Domestic nominal prices of final product, domestic input, and imported input are denoted by $P, U$, and $V$, respectively. Using the domestic input as numeraire, relative prices of the final output and the imported input are denoted by $\mathrm{p}=\mathrm{P} / \mathrm{U}$ and $\mathrm{v}=\mathrm{V} / \mathrm{U}$, respectively. The zero profit condition for final goods producers requires that

$$
P=a_{D} \cdot U+a_{I} \cdot V \text { or } P=a_{D}+a_{I} v
$$

where $a_{D}=D / X$ is the amount of domestic input per unit of output and $a_{I}=I / X$ is the amount of imported input per unit of output. Using the fact that $a_{D}=d / f(d)$ and $a_{I}=1 / f(d)$, it follows that the relative output price consistent with zero profits is given by

$$
p=(d+v) / f(d)
$$

The cost minimizing input ratio is determined by the requirement that the marginal technical rate of substitution equal the relative input price;

$$
(\partial F / \partial I) /(\partial F / \partial D)=\left[f(d)-d^{\prime} f^{\prime}(d)\right] / f^{\prime}(d) \equiv \phi(d)=v
$$

For example, if the input price ratio is $v_{0}$, then as illustrated in figure 1. the cost minimizing input ratio $d_{0}$ is determined by the point $A$ along the iso-quant $F(I, D)=1$ at which the marginal technical rate of substitution is equal to $v_{0}$. For any $v$, choice of $d=\phi^{-1}(v)$ clearly results in the minimum relative output price, $p(v)=\left[\phi^{-1}(v)+v\right] / f\left(\phi^{-1}(v)\right)$, that is consistent with zero profits for that input price ratio. 
Domestic content requirements may sometimes be set in terms of physical units, but because of difficulties in comparing physical units of different inputs and outputs, it is more common for a domestic content requirement to be stated in terms of share of domestic inputs in the value of final output. This share is given by

$$
\delta=a_{D}\left(a_{D}+v \cdot a_{I}\right)=d /(d+v)
$$

An effective domestic content requirement that sets a minimum value $\delta *$ for $\delta$ implies that the input ratio must be

$$
d *(\delta *, v)=(v \cdot \delta *) /(1-\delta *),
$$

which is greater than the input ratio $d=\phi^{-1}(v)$ that would minimize costs. The relative output price necessary to yield zero profits with such a content requirement,

$$
p^{*}(\delta *, v)=\left(d^{*}+v\right) / f\left(d^{*}\right)=[v /(1-\delta *)] / f((v \cdot \delta * /(1-\delta *))
$$

is greater than the price $p=\left[\phi^{-1}(v)+v\right] / f\left(\phi^{-1}(v)\right)$ that yields zero profits when producers minimize cost. For example, if the domestic content requirement necessitates an input ratio $d_{1}=d^{\star}\left(v_{0}, \delta *\right)>d_{0}=\phi^{-1}\left(v_{0}\right)$, then as illustrated in figure 1, production occurs at the point $B$ along the unit iso-quant, rather than at the cost minimizing point A. The relative output price that yields zero profits with this content requirement $p_{1}=p^{*}\left(v_{0} \delta^{*}\right)=$ $\left(d_{1}+v_{0}\right) / f\left(d_{1}\right)$, is indicated by the vertical intercept of the line passing through $B$ with slope equal to $-v_{0}$. This price is clearly greater than the price $p_{0}$ that yields zero profits under cost minimization, as indicated by the vertical intercept of the tangent to the unit iso-quant (with slope equal to $-v_{0}$ ) at the cost minimizing production point $A$. 
To enforce an effective domestic content requirement, there must be an incentive for compliance or a penalty for violation. When the final product is produced at home with imported inputs, it is natural for this incentive or penalty to be a tariff charged on imported inputs for producers violating the content requirement but rebated to producers complying with the requirement. 4 The penalty tariff necessary to enforce the content requirement must make the minimum cost for violators at least as great as the cost for those who comply. For example, in the situation illustrated in figure 1, an input tariff $\tau_{1}$ which makes the relative price of imported inputs for violators $v_{1}=\left(1+\tau_{1}\right) v_{0}$ is sufficient to enforce the content requirement because the isocost line for violators with intercept $p_{1}$ and slope $v_{1}$ passes below the unit isoquant. Producers who satisfy the content requirement, however, can produce at $B$ and enjoy unit costs of only $p_{1}$. The content requirement and the enforcement penalty make the isocost locus for unit cost of p 1 correspond to the kinked line that connects the points $p_{1}, B, E$ and $G$. with this isocost locus, the optimum production point is clearly $B$.

When the final good is produced abroad with exported domestic inputs, it is natural that the incentive for compliance be a penalty tariff (at an ad valorem rate $t$ ) on imports of the final product that do not satisfy the content requirement. Since $1+t$ imported units of final product subject to this tariff generate the same revenue as one unit satisfying the content requirement, producers will satisfy the requirement when the cost of producing $1+t$ units with a free choice of inputs is greater than the cost of producing 1 unit under the content requirement. In terms of figure 1, the penalty tariff rate $t_{1}$, Eor which the iso-quant $F(I, D)=1+t_{1}$ lies everywhere above the iso-cost line connecting $p_{1}, B, E$ and $G$ is sufficient to enforce the content requirement. 
It is an important property of content protection that the output price consistent with zero profits does not depend on the penalty used to enforce the content requirement, so long as the penalty is high enough to induce compliance. This property reflects the all-or-nothing nature of the penalty imposed for any violation of the content requirement. If the requirement is satisfied, no penalty at all must be paid and the zero profit price of a unit of output embodies only unit production cost and no penalty. Unit production cost, of course, exceeds the minimum achievable when producers are allowed free choice of inputs, but a content requirement generates no additional distortion by forcing a divergence between true social production cost (with the distored choice of inputs) and the price producers must charge to earn zero profit. 5

This property of content protection schemes accounts for their superiority over alternative policies for increasing the ratio of domestic input to imported input. Another policy that could achieve this same objective, in the case where the final output is produced at home using imported inputs, is an ad valorem tariff on imported inputs, with no rebates for producers. Specifically, to achieve the same input ratio $d_{1}$ as the content protection policy illustrated in figure 1, a tariff on the imported input would have to raise the domestic relative price of this input to the level $v_{2}$ determined by the slope of the unit iso-quant at the point B. Since this tariff is collected, producers must charge a price $\mathrm{p}_{2}$, determined by the vertical intercept of the tangent to the unit iso-quant at $B$, in order to earn zero profit. Since $p_{1}$ is the true social cost of producing a unit of output using the input combination at $B$, the difference $p_{2}-p_{1}$ measures an excess of price charged to consumers over true social production cost and implies a consumption distortion loss in excess of the distortion loss from content protection. 6 
Alternatively, the domestic input ratio could be raised to $d_{1}$ by paying a subsidy on the use of domestic inputs that raises the relative price of imported inputs to $v_{2}$. Since this subsidy reduces the output price for consumers (at the expense of the government) to below true social production cost, this subsidy creates consumption distortion loss in excess of the distortion loss from content protection. Because a content requirement avoids the excess consumption distortion loss generated by a tariff on imported inputs or a subsidy on domestic inputs, it is the second best policy for achieving a prescribed increase in the ratio of domestic input to imported input. This question remains, of course, why society should tolerate the production inefficiency that inevitably results from content protection in order to raise the ratio of domestic to imported input.

\section{Incentives for Improvements in Technical Efficiency}

The conclusion concerning the second-best optimality of a content protection policy requires qualification in situations where firms incur costs to maintain and improve the efficiency of their production processes. While analysis of such situations is not fully compatible with assumptions of perfect competition and a common constant-returns-to-scale technology for all firms, we can use the model of the preceding section to indicate the distortion of incentives for improvements in technical efficiency created by content protection. To this end, consider the reduction in unit production cost resulting from improvements in technical efficiency for a firm initially operating under the content protection policy described by the point $B$ in figure 1, which corresponds to the points $B$ in figures 2 and 3. An improvement in technical efficiency that allows for a small reduction $\Delta D<0$ in the amount of domestic unit used to produce a unit of output shifts the unit iso- 
quant downward in figure 2 to the iso-quant passing through the point G. To satisfy the domestic content requirement with the new technology, the firm must move up the unit iso-quant to the point $H$ that lies along the ray where $D / I=d_{1}$. Substitution of domestic for imported inputs in the move from $G$ to $H$ occurs at the rate $v_{2}$ which is equal to the marginal technical rate of substitution at $G$ and at $B$. The reduction in unit production cost made possible by the improvement in technical efficiency is measured units of domestic input by $\Delta p=p_{3}-p_{1}$, where $p_{1}$ and $p_{3}$ are the vertical intercepts of the lines passing through $B$ and $H$, respectively, with slopes equal to ${ }^{-v_{0}}$. To the first order of approximation, the reduction in unit production cost per unit reduction in required domestic input is given by

$$
\Delta p / \Delta D=1-\left[\left(v_{2}-v_{0}\right) /\left(v_{2}+d_{1}\right)\right]
$$

This result indicates the benefit to the firm and to society from an improvement in technical efficiency that saves domestic input, given that the content protection policy is in force. However, the benefit to society from this improvement in technical efficiency in the absence of the content protection policy is greater than the amount indicated by (8) because saving one unit of domestic input in the absence of this policy would be worth exactly one unit of domestic input. Since $\left(v_{2}-v_{0}\right) /\left(v_{2}+d_{1}\right)$ must be less than 1 , the distortion created by content protection cannot eliminate all of the benefit from improvements in technical efficiency that save domestic input. But, if the difference between $v_{2}$ and $v_{0}$ is large, the distortion could substantially reduce this benefit.

For improvements in technical efficiency that save imported input, the disortion created by content protection works in the opposite direction. As 


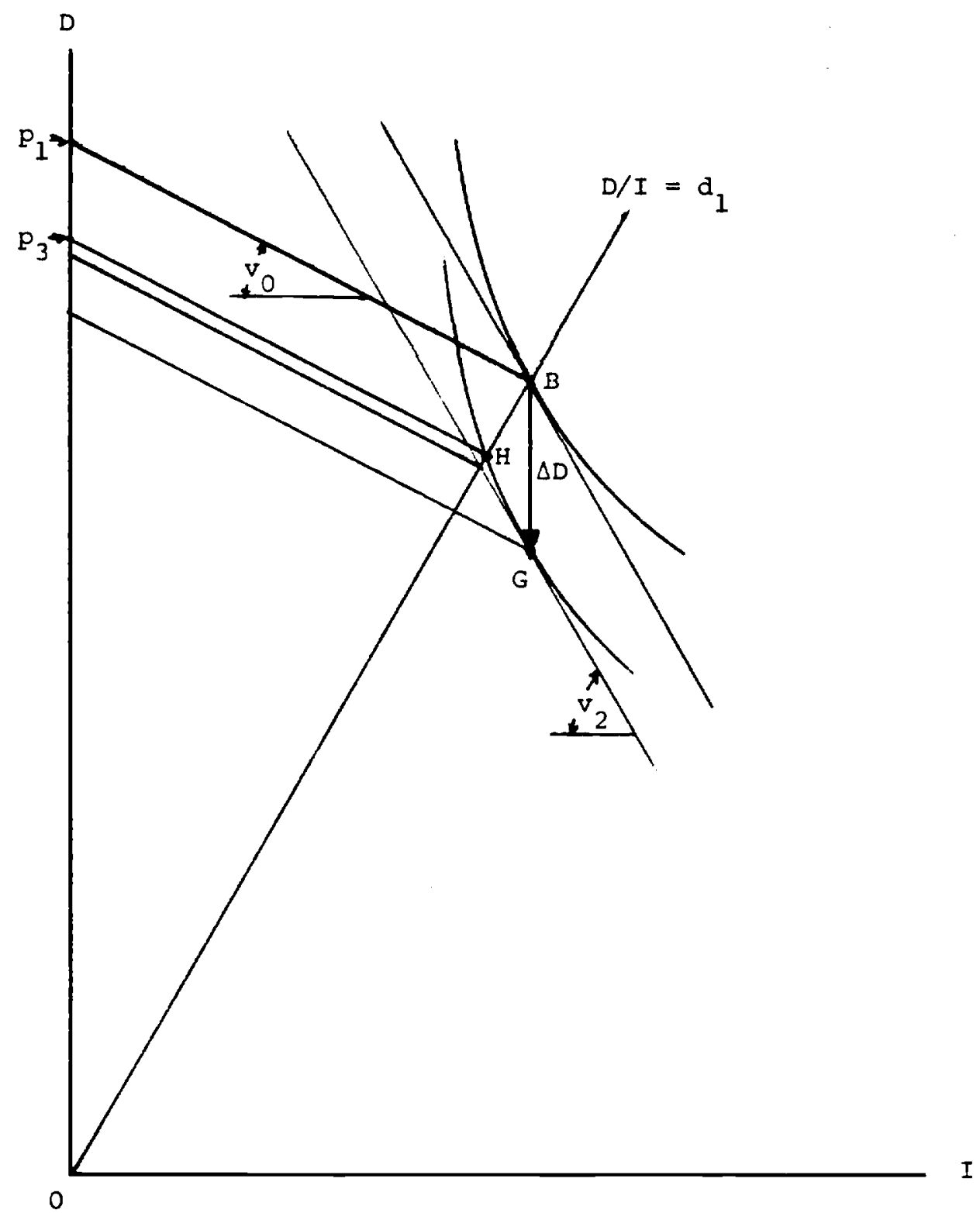

Fig.--2: The Effects of a Reduction in Domestic Input Necessary to Produce a Unit of Output. 
illustrated in figure 3, saving a small amount $\Delta I$ of imported input shifts the unit iso-quant to the left to the new iso-quant passing through the point $J$. At $J$, the firm can substitute increased imported input for reduced domestic input (at a rate equal to the marginal technical rate of substitution $v_{2}$ ) and still satisfy the domestic content requirement by producing at the point $K$. To the first order of approximation, the reduction in unit production cost resulting from this increase' in technical efficiency is

$$
\Delta p / \Delta I=v_{0}+\left(v_{2}-v_{0}\right) \cdot\left[d_{1} /\left(v_{2}+d_{1}\right)\right]
$$

In this result, the amount $v_{0}$ represents the social and private benefit of saving a unit of imported input in the absence of content protection. The additional amount $\left(v_{2}-v_{0}\right) \cdot\left[d_{1} /\left(v_{2}+d_{1}\right)\right]>0$ is the distortionary effect of content protection that arises because content protection forces a differential between the marginal value imported input in production (measured by the marginal technical rate of substitution $v_{2}$ ) and the price $v_{0}$ of this input.

Content protection does not create any distortion for a neutral improvement in technical efficiency that saves domestic and imported inputs in the same proportion as these inputs are initially used in producing a unit of output. Under content protection, however, economic incentives operate against neutral improvements in technical efficiency and in favor of improvements that save on imported input rather than domestic input. Diminished incentives for improvements in technical efficiency that save on domestic inputs provide a serious argument against use of content protection to provide temporary protection for infant industries or mature industries that need to regain international competitiveness since achievement of world standards of efficiency is likely to depend on efficiency in the use of domestic inputs. 


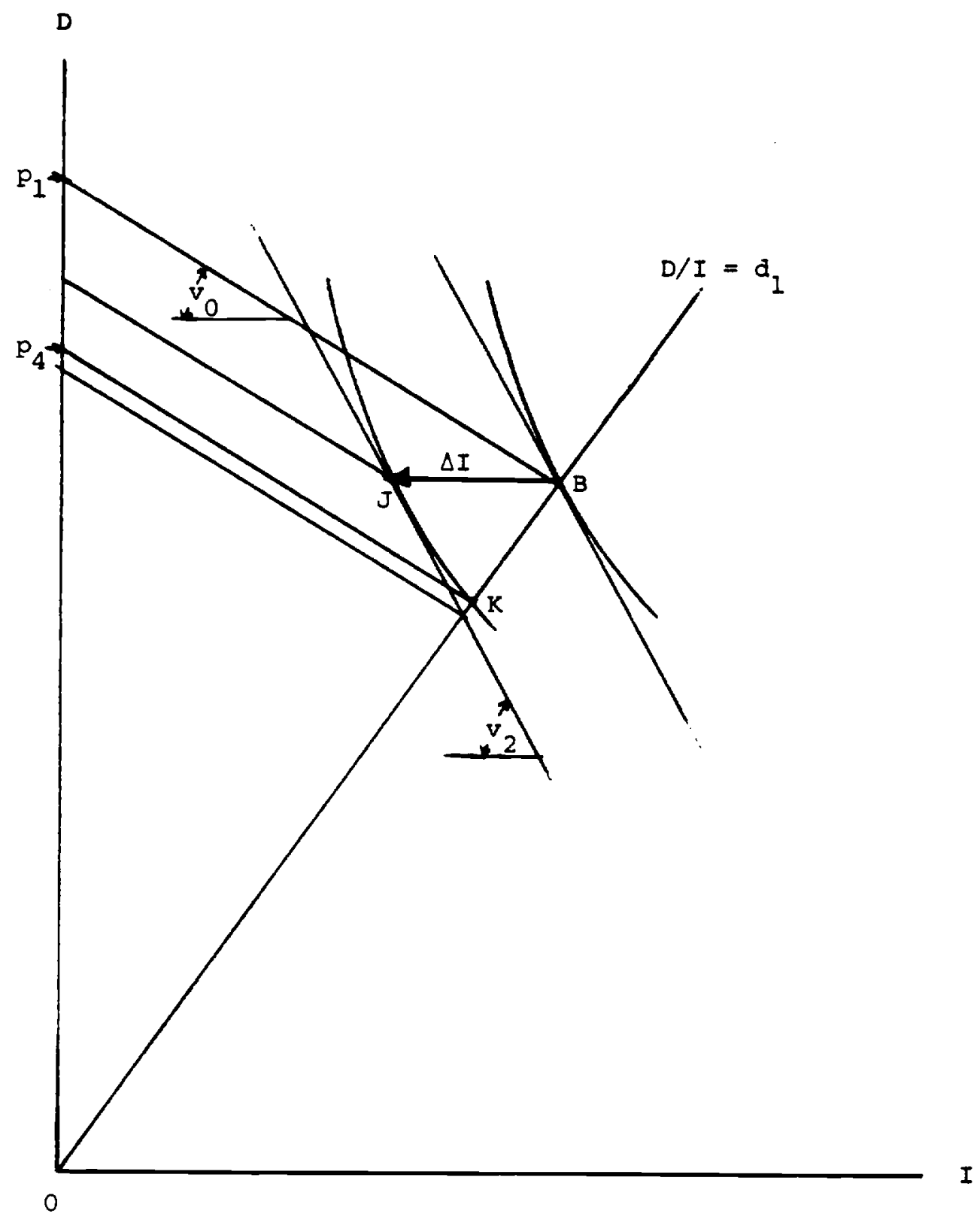

Fig.--3: The Effects of a Reduction in Imported Input Necessary to Produce a Unit of Output. 


\section{Price and Quantity of Domestic Input}

To assess these effects of content protection on the equilibrium price and quantity of the domestic input, assume that demand for the final product is a declining function, $H(P)$, of $i$ ts absolute price, with an elasticity of demand $\eta=(\mathrm{P} / \mathrm{H}) \mathrm{H}^{\prime}(\mathrm{P})$. The imported input is assumed to be in infinitely elastic supply at a given level of its absolute price, $v$. Supply of the domestic input is assumed to be an increasing function, $S(U)$, of its absolute price, with an elasticity of supply $\varepsilon=(U / S) \cdot S^{\prime}(U)$ when competition prevails in all markets, derived demand for the domestic input is determined by multiplying $x=H(P)$ by $D / x=a_{D}=d / f(d)$. Using the fact that $P=U \cdot[(d+v) / f(d)]$, it follows that

$$
D=(d / E(d)) \cdot H[(U d / f(d))+(V / f(d))]
$$

Using a hat " " to denote a proportionate change, the proportionate responses of $D$, to proportionate changes in $d, U$, and $v$, are given by

$$
\begin{aligned}
& \hat{D}=[1-\gamma+\eta \cdot(\delta-\gamma)] \cdot \hat{d} \\
& \hat{D}=[\eta \delta] \cdot \hat{U} \\
& \hat{D}=[(1-\delta) \cdot \eta] \cdot \hat{V}
\end{aligned}
$$

As before, $s=d /(d+v)$ is the share of domestic input in the cost of producing a unit of output. $\gamma=(d / f(d))$ ' $f$ '(d) is the elasticity of $x / I=$ $f(d)$ with respect to $d=D / I$.

When content protection is not in force, the input ratio $d$ is the cost minimizing input ratio $d=\phi^{-1}(v)$, where $\phi(d)=\left[f(d)-d \cdot f^{\prime}(d)\right] / f^{\prime}(d)$. Substituting $\phi(d)$ for $v$, it is easily shown that in the absence of content 
protection, the share of domestic input, $\delta=d /(d+v)$, is equal to $Y_{i}$

$$
\delta=d /(d+v)=d /(d+\phi(d))=d \cdot f \cdot(d) / f(d)=\gamma_{\text {, }} \text { when } v=\phi(d) \text {. }
$$

Further, since in the absence of content protection $d=\phi^{-1}(v)$, it follows that the proportionate change in the input ratio is given by

$$
\hat{d}=\sigma \cdot(\hat{U}-\hat{v})
$$

where $\sigma=(1-\gamma) \cdot\left[f^{\prime}(d) / d \cdot f^{\prime \prime}(d)\right]<0$ is the elasticity of substitution between domestic and imported inputs. This result together with (11), (12), and (13) implies that

$$
\begin{aligned}
& \hat{D}=[n \delta+(1-\gamma) \cdot \sigma] \cdot \hat{U} \\
& \hat{D}=[(1-\delta) \cdot \eta-(1-\gamma) \cdot \sigma] \cdot \hat{V} .
\end{aligned}
$$

Equation (17) reveals the condition for a tariff on the imported input, which induces a positive $\hat{v}$, to increase demand for the domestic input: the elasticity of substitution between the domestic and the imported input must be greater in absolute value than the price elasticity of demand for the final output. Otherwise, the negative effect on the derived demand for $D$ from the increase in the output price caused by the increased cost of the imported input will outweigh the positive substitution effect of the increase in the price of the imported input relative to the domestic input. It follows that suppliers of the domestic input will benefit from a tariff imposed on the imported input only when the elasticity of substitution between domestic and imported inputs is greater (in absolute value) than the price elasticity of demand for the final product.

Under content protection, the input ratio is no longer $d=\phi^{-1}(v)$, but rather $d=d^{*}\left(\delta^{*}, v\right)=\left(v \cdot \delta^{*}\right) /\left(1-\delta^{*}\right)$. With a fixed content requirement, 
therefore,

$$
\hat{\mathrm{d}}=\hat{\mathrm{v}}=\hat{\mathrm{v}}-\hat{\mathrm{U}}
$$

Further, the proportionate response of $d$ to a proportionate change in the content requirement is

$$
\hat{d}=\left[1 /\left(1-\delta^{*}\right)\right] \cdot \hat{\delta} *
$$

These results together with (11), (12), and (13), determine the proportionate response of demand for the domestic input to proportionate changes in $U$, $v$, and $\delta *$ when content protection is in force:

$$
\begin{aligned}
& \hat{D}=\left[\eta \delta *-(1-\gamma)+\eta \cdot\left(\gamma-\delta^{*}\right)\right] \cdot \hat{U} \equiv \Gamma \cdot \hat{U} \\
& \hat{D}=\left[\left(1-\delta^{*}\right) \cdot \eta+(1-\gamma)-\eta \cdot\left(\gamma-\delta^{*}\right)\right] \cdot \hat{V} \equiv \Lambda \cdot \hat{V} \\
& \hat{D}=\left[[1-\gamma+\eta \cdot(\delta *-\gamma)] /\left(1-\delta^{*}\right)\right] \cdot \hat{\delta} * \equiv \Omega \cdot \hat{\delta} *
\end{aligned}
$$

In all of these results, the difference between $\gamma=d^{\prime} f^{\prime}(d) / f(d)$ and $\delta$ is important. $\gamma$ measures the share of domestic input when the price of imported input equals the marginal technical rate of substitution; whereas $\delta$ * is the minimum required share of domestic input when imported input is valued at its market price. Without a content requirement, $\gamma=\delta$. When the content requirement is more than marginally effective, however, the narginal technical rate of substitution is greater than the market relative price of the imported input and hence $\delta *$ is $>\gamma$.

It follows that starting with a content requirement that is on the margin of effectiveness, a small proportionate increase $\delta *$ causes an equal proportionate increase in demand for the domestic input; ${ }^{7}$ that is

$$
\hat{D}=[(1-\gamma) /(1-\delta *)] \cdot \hat{\delta} *=\hat{\delta} * \text { when } \delta *=\phi^{-1}(v) /\left(\phi^{-1}(v)+v\right)
$$


The reason for this equal proportionate effect is that with only a marginally effective content requirement, a small increase in $\delta *$ has only a second order of small effect on unit cost and output price. The direct first order effect of an increase in $\delta \star$ on demand for the domestic input, therefore, is not offset by any first order indirect effect of a reduction in final output demand due to an increase in the final output price.

When the content requirement is more than marginally effective, an increase in $\delta \star$ causes a first order increase in the final output price to the extent of $\hat{\mathrm{P}}=\left[\left(\hat{\delta}^{\star}-\gamma\right) /(1-\delta \star)\right] \cdot \hat{\delta} \star$. This increase in $\mathrm{P}$ at least partially offsets the direct effect on the demand for domestic input of the increase in $\delta \star$. When content protection is sufficiently stringent to produce a large difference between $\delta \star$ and $\gamma$, it is possible that further increases in $\delta \star$ will reduce demand for the domestic input. For this not to happen, the price elasticity of demand for the final product must not be too large; specifically, for $\Omega$ defined in (22) to be positive, it is necessary that

$$
|\eta|<(1-\gamma) /(\delta \star-\gamma)
$$

Since $\delta * \leqslant 1$, it is clear that this condition is always satisfied if $|n|<1$. The the equilibrium responses of $D$ and $U$ to changes in $\delta *$ depend on the elasticity of supply of the domestic input. Specifically, equating $\hat{D}=\varepsilon \cdot \hat{U}$, to $\hat{D}=\Gamma \cdot \hat{U}+\Omega \cdot \hat{\delta}$, it follows that the equilibrium responses of $U$ and $D$ to a change in the content requirement are given by

$$
\begin{aligned}
& \hat{U}=[1 /(\varepsilon-\Gamma)] \cdot \Omega \cdot \hat{\delta} \star \\
& \hat{D}=[\varepsilon /(\varepsilon-\Gamma)] \cdot \Omega \cdot \hat{\delta} \star
\end{aligned}
$$

Since $\varepsilon$ is $>0$ and $\Gamma$ is $<0$, an increase in $\delta \star$ will increase both the equilibrium price and the equilibrium quantity of the domestic input if and 
only if $\Omega$ is positive for which the necessary and sufficient condition is given by (24).

In summary, when competition prevails in all markets, imposition of a marginally effective content requirement always protects suppliers of the domestic input by raising demand for this input thereby increasing its equilibrium price and the quantity employed in the industry subject to the content requirement. In contrast, a tariff imposed on the imported input benefits suppliers of the domestic input only when the elasticity of substitution between domestic and imported inputs is greater (in absolute value) than the price elasticity of demand for the final product. Increases in the required share of domestic content above the marginally effective level will further increase the equilibrium price and quantity of the domestic input when the price elasticity of demand for the final product is less (in absolute value) than the critical value $(1-\gamma) /(\delta *-\gamma)$. For moderate price elasticities of demand for the final product, this condition can be violated only when a very stringent content requirement forces a substantial divergence between $\delta *$ and $\gamma$. Hence, over a fairly broad range, it is reasonable to expect that increases in the required share of domestic content will provide increased protection to suppliers of the domestic input.

5. Differences between Domestic and Foreign Producers

In some situations where content protection is used or contemplated, such as the U. S. auto industry, domestic firms typically use a much higher ratio of domestic to imported input than foreign firms who export to the domestic market. To deal with this case, it is convenient to assume that foreign firms use both domestic and imported (or foreign) inputs to produce their output $x$, in accord with the production technology described in section 2 , while 
domestic firms produce their output, $Y$, using a only fixed amount, b, of domestic input per unit of output. outputs of domestic and foreign firms are assumed to be good but imperfect substitutes. The demand for foreign output is $X=H(P, R)$, where $P$ is the absolute price of the foreign product and $R$ is the absolute price of the domestic product, $\omega=(\mathrm{P} / \mathrm{H}) \cdot(\partial \mathrm{H} / \partial \mathrm{P})<0$ is the elasticity of demand for the foreign product with respect to its own price, and $\zeta=(\mathrm{R} / \mathrm{H}) \cdot(\partial \mathrm{H} / \partial \mathrm{R})>0$ is the elasticity of demand for the foreign product with respect to the absolute price of the domestic product. The demand for domestic output is $Y=N(R, P)$, where $\nu=(R / N) \cdot(\partial N / \partial R)<0$ is the elasticity of demand for the domestic product with respect to its own price, and $\mu=(\mathrm{P} / \mathrm{N}) \cdot(\mathrm{dN} / \partial \mathrm{P})>0$ is the elasticity of demand for domestic product with respect to the price of the foreign product. Imported (or foreign) input is assumed to be in infinitely elastic supply at a given value of its absolute price, v. Supply of the domestic input is $S(U)$, with an elasticity of $\varepsilon=(U / S(U)) \cdot S^{\prime}(U)>0$.

Given these assumptions, the derived demand for the domestic input may be expressed as

$$
D=(d / f(d)) \cdot H(P, R)+b \cdot N(R, P),
$$

where $d$ is the ratio of domestic to imported input used by foreign producers, $\quad P=(U \cdot d / f(d))+(V / f(d))$, and $R=b \cdot U$. The general expression for the proportional change in the derived demand for the domestic input is

$$
\hat{D}=\alpha \cdot[(1-\gamma) \cdot \hat{d}+\omega \cdot \hat{P}+\zeta \cdot \hat{R}]+(1-\alpha) \cdot[v \cdot \hat{R}+\mu \cdot \hat{P}],
$$

where $\alpha=(d / E(d)) \cdot H(P, R) / D$ is the fraction of total demand for domestic input accounted for by foreign firms; where, as before, $\gamma=d \cdot f \cdot(d) / f(d)$; and where 


$$
\begin{aligned}
& \hat{P}=(\delta-y) \cdot \hat{\mathrm{d}}+\delta \cdot \hat{U}+(1-\delta) \cdot \hat{\mathrm{V}} \\
& \hat{\mathrm{R}}=\hat{U} .
\end{aligned}
$$

Using these results and (19), we may derive the expression for the proportionate change in the derived demand for the domestic input lat constant values of $U$ and $V$ ) in response to a proportionate change in the domestic content requirement;

$$
\hat{D}=(1 /(1-\delta *)) \cdot\{\alpha \cdot(1-\gamma)+(\delta *-\gamma) \cdot[\alpha \omega+(1-\alpha) \cdot \mu]\} \cdot \hat{\delta} *
$$

It follows that the condition for an increase in the domestic content requirement to increase demand for the domestic input is

$$
|\omega|-[(1-\alpha) \cdot \mu / \alpha]<[(1-\gamma) /(\delta *-\gamma)]
$$

Since the right hand side of (32), which is identical to the right hand side of (24), has a value of infinity when $\delta *=Y$, it follows that imposition of a marginally effective content requirement for foreign firms necessarily increases demand for the domestic input. As the content requirement rises above the marginally effective level, further increases in $\delta *$ diminish foreign firms demand for domestic input by raising the price and decreasing the demand for the output of these firms. This effect is captured by the term $|\omega|$ on the right hand side of (32). This effect, however, is at least partially offset by the increased demand of domestic firms for domestic input resulting from the shift of final product demand toward domestic firms due to the increased price of the output of foreign firms. This effect is captured by the term $-(1-\alpha) \cdot \mu / \alpha$ on the right hand side of (32). It follows that if the reduction in demand for the foreign firms' product due to a price increase is largely a shift of demand toward the product of domestic 
firms (which use a higher ratio of domestic input than foreign firms), then an increase in the required share of domestic content for foreign firms is likely to increase demand for the domestic input and hence benefit suppliers of this input. Suppliers of the domestic input can lose at the margin from an increase in the domestic content requirement only when the required share of domestic content already significantly exceeds the share foreign firms would voluntarily choose and when an increase in the price of the foreign firms' product significantly diminishes total demand for the product of foreign and domestic firms.

\section{Non-Competitive Behavior}

Returning to the simpler case where all firms produce the same product using the same technology, it is interesting to consider the effects of content protection when markets for the final product or the domestic input are not competitive. We continue with the assumption that the imported input is competitively supplied at a constant absolute price. Only minor modifications of the preceding analysis are required to deal with monopoly power in the final product market, if this power was already being exercised prior to the introduction of content protection. For a given demand function, $X=H(P)$, there is a marginal revenue function, $x=$ $J(M)$, which expresses the relationship between output sold, $x$, and the monopolist's marginal revenue, $M^{8}$ The monopolist equates marginal revenue to unit production cost, implying that derived demand for the domestic input is determined by

$$
D=(d / f(d)) \cdot J[(U d d / f(d))+(V / f(d))]
$$


This derived demand relationship is identical to the derived demand relationship (10) for the competitive case, except that the marginal revenue function $J$ has replaced the demand function $H$. All results for the competitive case, with both free input choice and with content protection, remain valid, provided that the elasticity of demand for the final product, $\eta=(P / H(P)) \cdot H^{\prime}(P) ; \quad$ is everywhere replaced by the elasticity of the marginal revenue function, $\quad \xi=(M / J(M)) \cdot J^{\prime}(M)$.

of course, a monopolist will generally sell a smaller amount of final product and use a smaller amount of domestic input than would be the case under competition. Introduction of content protection, however, need not affect these differences between monopoly and competition in the final product market because content protection directly affects the cost conditions of final goods producers, not the conditions of demand for their output. Monopsony in the domestic input market can be handled in much the same way as monopoly in the final product market. The supply function for the domestic input, $S(U)$, implies a marginal factor cost function, $Q(W), \quad$ which specifies the relationship between the quantity of this input and its marginal cost, w, for a purchaser who recognizes that supply price rises with the number of units purchased. The analysis of section 4 goes through, when the price of domestic input, $U$, is everywhere replaced by its marginal factor cost, $W$, and when the elasticity of the supply function, $\varepsilon=(U / S(U)) \cdot S^{\prime}(U)$ is everywhere replaced by the the elasticity of the marginal factor cost function, $\lambda=(W / Q(W)) \cdot Q^{\prime}(W)$. As with the case of monopoly in the final product market, monopsony in the domestic input market will generally reduce the equilibrium price and quantity of the domestic input to below the levels that would prevail under competition. However, since content protection does not directly affect the conditions of supply of the domestic input, it need 
not affect, in an important way, these differences between the monopsonistic and the competitive equilibrium in the market for the domestic input.

Content protection interacts in an important way with monopoly in the final product market and monopsony in the domestic input market if it creates monopoly and monopsony power in these markets when it would not otherwise have existed. This might happen, for example, if a single domestic firm which used a high ratio of domestic to imported input originally competed with foreign firms that found it efficient to use lower ratios of domestic to imported input. A content protection requirement that forced the foreign firms to use much higher ratios of domestic input to imported input than they would otherwise choose might remove these firms as competitors both in the market for the final product and in the market for the domestic input, thereby allowing the domestic firm to exercise both monopoly power in the final product market and monopsony power in the market for the domestic input. Exercise of monopoly power by suppliers of the domestic input against demanders of this input is almost always affected by content protection because content protection directly affects the elasticity as well as the level of derived demand for the domestic input, as illustrated in figures 4 and 5. In these figures, the curve labeled $D(U)$ shows the derived demand for the domestic input when producers exercise free choice of input combinaton. The curve labeled $D^{\star}(U)$ shows the derived demand for domestic input when the content requirement $\delta>\delta \star$ is imposed. It is assumed that this content requirement is only marginally effective, in the sense that $\delta *$ is equal to the share of domestic input that producers voluntarily choose in the equilibrium that prevails before content protection, with suppliers of the domestic input optimally exploiting their monopoly power. In figure 4, it is assumed that the elasticity of substitution between domestic and foreign 


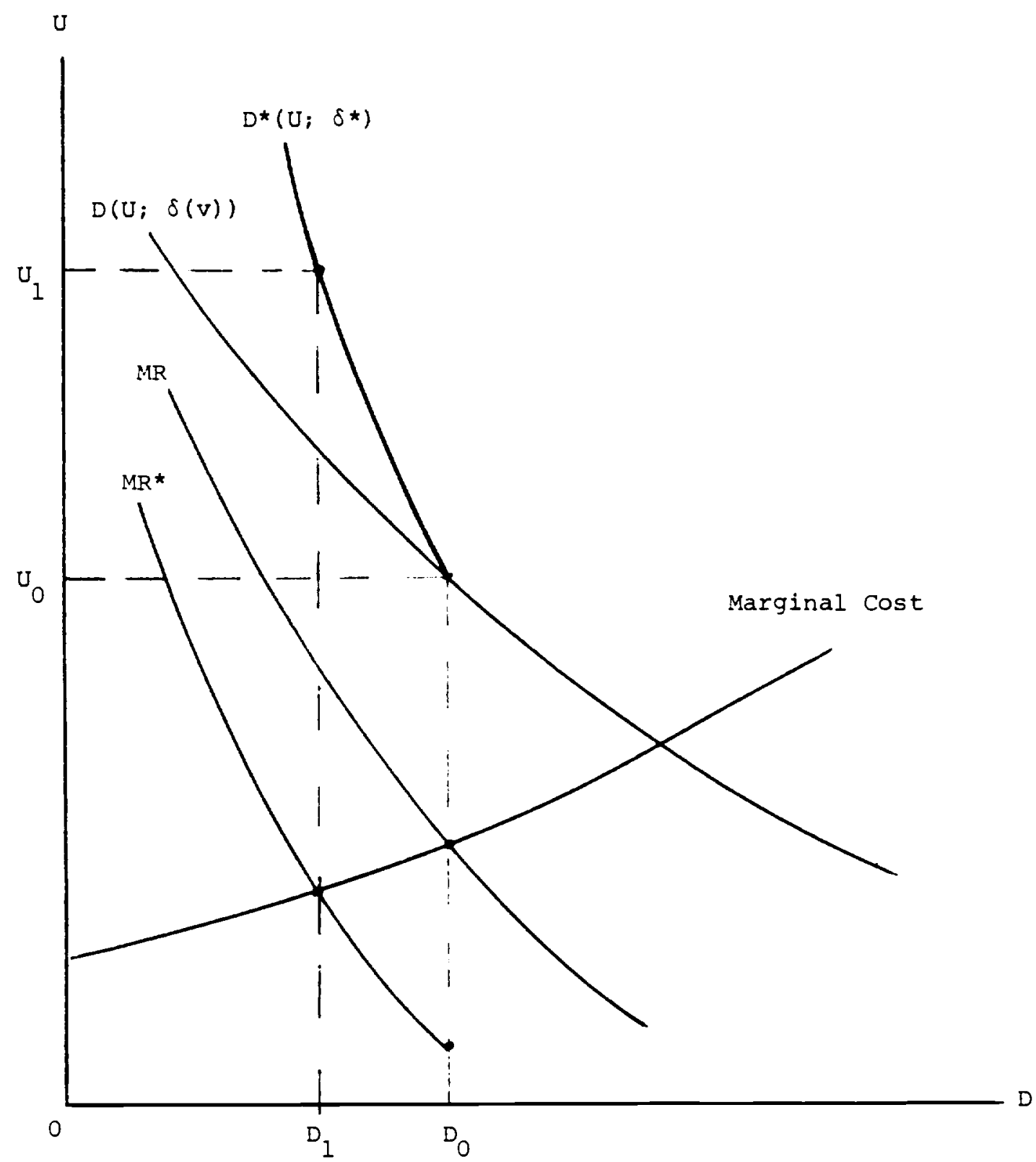

Fig.--4. Marginally Effective Content Protection when the Supplier of the Domestic Input Acts as a Monopolist and $|\sigma|>1$. 


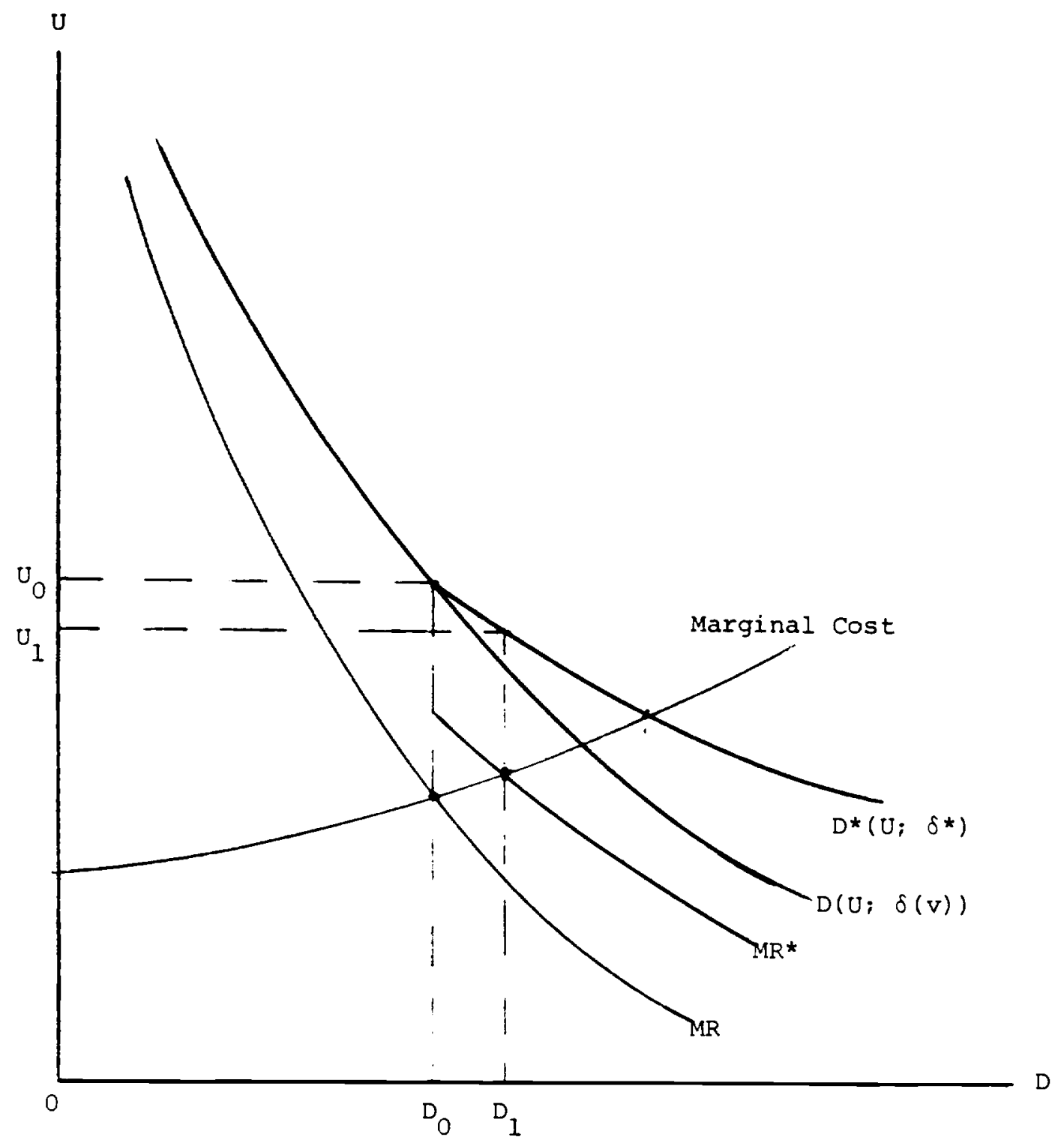

Fig.--5. Marginally Effective Content Protection when the supplier of the Domestic Input Acts as a Monopolist and $|\sigma|<1$. 
inputs, $\sigma$, is greater than one in absolute value. This implies that the share of the domestic input grows as we move down along the $D(U)$ curve. The $D^{\star}(U)$ curve therefore corresponds to the $D(U)$ curve below the initial equilibrium price and lies to the right of this demand curve above the initial equilibrium price. In contrast, in figure 5, it is assumed that $|\sigma|$ is $<1$. This implies that the share of domestic input declines as we move down along the $D(U)$ curve. The $D^{*}(U)$ curve therefore corresponds to the $D(U)$ curve above the initial equilibrium price, and lies to the right of this demand curve below the initial equilibrium price. Constructing the marginal revenue curves that are appropriate with and without marginally effective content protection, it is apparent from figure 4 that when $|\sigma|>1$, marginally effective content protection raises the monopoly price and lowers the monopoly quantity of the domestic input. In contrast, as illustrated in figure 5, when $|\sigma|$ is $<1$, marginally effective content protection lowers the monopoly price and raises the monopoly quantity of the domestic input. 9 Despite the differences in the direction of change in the monopoly equilibrium price and quantity of the domestic input, depending on the elasticity of substitution, the monopolistic supplier of the domestic input always gains from the introduction of marginally effective content protection. The monopolist clearly cannot lose because the initial monopoly equilibrium point remains available. The monopolist actually gains from marginally effective content protection by moving away from this initial equilibrium point in whichever direction allows him to take advantage of marginally effective content protection. Increases in the domestic content requirement above the marginally effective level are clearly beneficial to the monopolistic supplier of the domestic input so long as they increase the demand for this input at the price that the monopolist is already charging. 


\section{Conclusions and Extensions}

The main conclusions of the preceding analysis may be summarized as follows. First, content protection creates a production distortion by forcing an inefficient choice of domestic and imported (or foreign) inputs, but it does not create an excess consumption distortion by forcing a divergence between social production cost (given the inefficiency in input choice) and output price. Second, content protection biases investments in improvements in technical efficiency away from improvements that save domestic input and toward improvements that save imported (or foreign) input. Third, under competitive conditions, introduction of a marginally effective content requirement increases demand for the domestic input and benefits suppliers of this input. Fourth, increases in the domestic content requirement above the marginally effective level further increase demand for the domestic input and further benefit suppliers of this input provided that the price elasticity of demand for the final product is smaller (in absolute value) than a critical value that varies inversely with the stringency of the content requirement. Fifth, the consequences of monopoly in the final product market and monopsony in the domestic input market are not materially affected by content protection unless such a policy creates a monopoly or monopsony situation when one would not otherwise have existed. Sixth, content protection does in general enhance the monopoly power of suppliers of the domestic input.

Among these conclusions, those that deal with effects on the suppliers of domestic inputs are sensitive to the assumption of a single domestic input and hence a unity of interests among the suppliers of this input. Suppose instead that the domestic input $D$ is produced by two more basic inputs, $L$ and $K$, in accord with a neo-classical, linear homogeneous production function, 
$D=G\left(L_{D}, K_{D}\right)$. Suppose further that these two inputs are mobile between industries, are fixed in aggregate supply, and are used in the neo-classical, linear homogeneous production function $\mathrm{Z}=\mathrm{H}\left(\mathrm{L}_{\mathrm{Z}}, \mathrm{K}_{\mathrm{Z}}\right)$ to produce the economy's other genic output, $\mathrm{Z}$, whose absolute price is denoted by $T$. Under these assumptions, the economy may be thought of as producing two products, $D$ and $\mathrm{Z}$, with absolute prices $U$ and $T$, using the technology of the standard, Hechscher-Ohlin-Samuelson model.10 Content protection which increases the demand for $D$ at given values of all prices will increase the equilibrium relative product price U/T. Hence, the combination of $L$ and $K$ used in $D$ (which earns $U$ for each unit of $D$ produced) will gain relative to the combination of $L$ and $K$ used in $Z$ (which earns $T$ per unit of $\mathrm{Z}$ produced). When we look at individual factors, however, the Stolper-Samuelson theorem tells us that the reward to the factor used intensively in $D$ will rise relative to $U$ and $T$, while the reward to the other factor declines in terms of both products. With this production structure, therefore, it is the factor used intensively in $D$ that is the beneficiary of content protection.

Modifying the assumptions of the preceding paragraph, suppose that only the factor $L$ is mobile between $D$ and $Z$ and that $K$ is specific to the industry where it is employed. The production structure for $D$ and $Z$ is now described by the specific capital or Viner-Ricardo model.11 Content protection which raises the demand for $D$ at given prices will, as in Heckscher-Ohlin-Samuelson structure of the preceding paragraph, increase the equilibrium relative product price $U / T$. The combination of $L$ and $K$ used in $D$ will gain relative to the combination of $L$ and $K$ used in $Z$. with respect to individual factors, the reward to $K_{D}$ will rise relative to $U$ and $T$, the reward to mobile $L$ will rise relative to $T$ but fall relative 
to $\mathrm{U}$, and the reward to $\mathrm{K}_{\mathbf{Z}}$ will fall relative to $\mathbf{T}$ and $\mathrm{U}$. Thus, $\mathrm{K}$ specific to $D$ will be the clear winner from content protection, with $K$ specific to $Z$ the clear loser, and mobile $L$ somewhere in between. Modifying further the technology for production of $x$ to allow for different substitution relations between imported inputs and particular domestic inputs, the production function $x=F(I, D)$ might be written as $x=J\left(I, L_{D}, K_{D}\right)$. With this technology for $x$ production, the effect of content protection on demands for $L_{D}$ and $K_{D}$ at given prices depends on the nature and strength of complementarity and substitution relations among the factors cooperating to produce $x$. If, for example, $L_{D}$ was a strong complement for $I\left(J_{I L}>0\right)$ while $K_{D}$ was a strong substitute for $I$ and $L\left(J_{I K}\right.$ $<0$ and $\left.J_{L K}<0\right)$, then content protection might increase demand for $K_{D}$ while reducing demand for $L_{D}$. Equilibrium effects on rewards to individual domestic factors would depend additionally on the specificity or mobility of $L_{D}$ and $K_{D}$ and the intensity with which these factors are used in other domestic production activities. Rather than enumerating the possible outcomes, suffice it to emphasize that the gains and losses of individual domestic factors from content protection depend on the details of the production stricture of the economy.

Finally, it is important to note two assumptions of the preceding analysis that are not always satisfied when content protection is an active issue. First, foreign firms induced to establish domestic production facilities because of content protection may not pay the same price or face the same conditions in the market for domestic factors as domestic firms in their industry. In developing countries, foreign firms typically pay higher wage rates than domestic firms. It is argued that these higher wage rates attract a queue of unemployed workers who wait for a high wage job at a foreign firm rather than accepting a lower wage job at a domestic firm. If so, then 
content protection that increases the number of high wage jobs at foreign firms may have a significant efficiency cost in terms of higher unemployment. For the U.S. auto industry, this situation is probably reversed: the effect of content protection on automobile prices, on wages of auto workers and on profits of U.S. auto firms depends on whether foreign firms induced to locate production facilities in the U.S. accept the high wage rates and work rules currently prevailing at U.S. firms. Second, constant returns to scale is not an accurate assumption for automobile industries in developing countries that have frequently been subjects of content protection and may not be an accurate assumption for other industries in these countries or for industries in developed countries that are actual or potential subjects of such policies. Reasonable efficiency in final assembly and in manufacture of some automobile parts and components may be achievable at a scale commensurate with final sales (and desirable product diversity) in the markets of the largest developing countries. Efficient manufacture of some automobile components (with allowance for desirable product diversity), however, apparently requires a scale achieved only in the largest automobile markets (North America, Europe, and Japan).12 stringent domestic content requirements that force small scale production of these automobile components necessarily have significant efficiency costs beyond the increase in unit production cost indicated by the analysis in section 2. The same point applies to content requirements in other industries where scale economies remain important for some components of the final product at scales beyond the size of the domestic market. Moreover, when scale economies are important, there is the danger that content protection will artificially create a "natural monopoly" in which a single, efficient domestic producer keeps out domestic rivals (who cannot reach efficient scale) and is freed of competition from foreign firms who do not meet the content requirement. 


\section{Footnotes}

1. The United States, for example, permits foreign assembled products normally subject to tariffs or other import restraints to enter the U.S. with reduced duties if they embody a minimum specified value of U.S. produced components.

2. Analyses of content protection schemes are also provided by Corden (1971, pp. 45-50), by Johnson (1972, pp. 285-306) for the case of the Canadian auto industry before the Canada-U.S. auto pact, and by Munk (1969) for automobile industries in several Latin American countries. 3. Grossman (1981) writes the production function as $X=F\left(L, M^{+} M^{*}\right)$ where $L$ is a domestic primary input called "labor" and $M$ and $M *$ are domestic and imported material inputs that are perfect substitutes in producing the final product. Grossman specifies that a physical content requirement sets a maximum ratio of $M^{\star}$ to $M$ and that a value (or share) content requirement sets a maximum value of $P_{m}^{*} \cdot M / P \cdot X$ where $P_{m}^{*}$ is the price of the imported material input and $P$ is the output price. While this formulation may be reasonable for some industries subject to content protection, I would argue that the production function (1) which allows a nore flexible representation of substitution possibilities between domestic and imported inputs is more appropriate for a general analysis of content protection. Moreover, in most domestic content schemes, the cost of primary domestic inputs, as well as purchased domestic material inputs or components, is allowable in the calculation of domestic content. The present analysis of content protection is consistent with this practice rather than with Grossman's assumption that only domestic material inputs count as domestic content. 
4. To protect domestic firms whose costs are raised by the content requirement from foreign firms that produce entirely abroad it will generally be necessary either to prohibit imports of foreign goods that fail to meet the content requirement or charge a suitable tariff on such goods. In some cases, protective tariffs on the final product may already be in force before content protection is introduced. Then, as Corden (1971) notes, introduction of content protection will reduce effective protection for domestic producers of the final product by raising the price they must pay for purchased domestic inputs.

5. In his analysis of the content protection scheme for the Canadian auto industry, Johnson (1972) concludes, "The content requirement, when effective, forces the manufacturer to spend the increased profit he would obtain lfrom remission of duties on imported inputs], not on lower prices to the consumer, but on the excess cost of parts production in Canada." This conclusion is only partially correct. Some fraction of the remitted penalty tariff is effectively absorbed by the increase in unit production cost for firms that satisfy the domestic content requirement. However, provided that competition prevails, the part of the remitted penalty tariff that is not absorbed by this increased cost is passed through to purchasers of the final product. 6. There is some consumption distortion loss from content protection because the price to consumers is raised above the price that would prevail in the absence of such protection. There is not, however, any excess consumption distortion loss from content protection due to a divergence between true social domestic production cost and the price charged to consumers. 7. This result differs from Grossman's conclusions (see his propositions 3 and 5) that a "small" (marginally effective) content requirement could raise or lower domestic value added. The reason for the difference is in Grossman's 
specification of technology and in his definition of the magnitude to which the domestic content requirement is applied. Specifically, Grossman includes only domestic material inputs in his definition domestic content that satisfies the content requirement. A marginally effective content requirement in his model increases the quantity of the domestic material input, but may reduce value added from the primary domestic input sufficiently to reduce total domestic value added.

8. For the purpose of this discussion, it is assumed that marginal revenue, M, is a well-defined, monotonically decreasing function of output, $x$. 9. Grossman (proposition 6) concludes that imposition of a marginally effective content requirement will always induce a monopolistic supplier of the domestic material input to raise his price and reduce his quantity. This is because in Grossman's model the demand curve facing the supplier of the domestic material input is infinitely elastic at the world market price of the imported input before content protection is imposed. When a marginally effective domestic content requirement is imposed, the demand curve facing the domestic supplier of the material input has finite elasticity at and in a region to the left of the old equilibrium point without this requirement. At the old equilibrium, therefore, marginal revenue must be less than marginal cost when the marginally effective content requirement is imposed, implying that the monopolistic supplier of the domestic material input will increase his price and reduce his quantity.

10. See Jones (1965) for a clear discussion and summary of the properties of this model.

11. See Jones (1971), Mayer (1974) or Mussa (1974) for an exposition of the essential properties of the model. 
12. Munk (1969) cites evidence from the 1950's and 1960's that indicates differing degrees of scale economies for different processes in automobile manufacturing, with some meaningful economies for total vehicle production remaining at a scale of three or four hundred thousand vehicles per year. The shift toward production of "world cars" by leading manufacturers suggests that scale economies in automobiles today are at least as important as they were a decade or two decades ago. 
References

Corden, W. M., 1971, The Theory of Protection. Oxford: Oxford University Press.

Grossman, Gene M., 1981, "The Theory of Domestic Content Protection and Content Preference," quarterly Journal of Economics, 96, no. 4 (November), $583-603$

Johnson, Harry G., 1972, Aspects of the Theory of Tariffs. Cambridge, Massachusetts: Harvard University Press.

Jones, Ronald W., 1971, "The Three Factor Model in Theory, Trade and History," in Bhagwati, et. al. (eds.), Trade, the Balance of Payments and Growth. Amsterdam: North Holland.

Jones, Ronald W., 1965, "The Structure of Simple General Equilibrium Models," Journal of Political Economy, 73, no. 4 (August), 557-572.

Mayer, Wolfgang, 1974, "Short-Run and Long-Run Equilibrium for a Small Open Economy," Journal of Political Economy, 82, no. 5 (September), 955-967. Munk, Bernard, 1969, "The Welfare Costs of Content Protection: The Automobile Industry in Latin America," Journal of Political Economy, 77, no 1 (February), 85-98.

Mussa, Michael, 1974, "Tariffs and the Distribution of Income: The Importance of Factor Specificity, Substitutability and Intensity in the Short and Long Run," Journal of Political Economy, 82, no. 6 (November), 1191-1203. 